\title{
Conceptual Measures of Oral Health Literacy and Oral Health Behaviour among Street Hawkers and Fruit Vendors in Wardha, Maharashtra
}

\author{
Gargi C. Nimbulkar ${ }^{1}$, Ankita Chandarana ${ }^{2}$, Lalrin Sangi ${ }^{3}$, Sakshi Patel ${ }^{4}$, Shravani Deolia ${ }^{5}$, Amit Reche ${ }^{6}$
}

\begin{abstract}
${ }^{1}$ Department of Public Health Dentistry, Sharad Pawar Dental College, DMIMS, Sawangi (Meghe), Wardha, Maharashtra, India. ${ }^{2}$ Department of Public Health Dentistry, Sharad Pawar Dental College, DMIMS, Sawangi (Meghe), Wardha, Maharashtra, India. ${ }^{3}$ Department of Public Health Dentistry, Sharad Pawar Dental College, DMIMS, Sawangi (Meghe), Wardha, Maharashtra, India. ${ }^{4}$ Department of Public Health Dentistry, Sharad Pawar Dental College, DMIMS, Sawangi (Meghe), Wardha, Maharashtra, India. ${ }^{5}$ Department of Public Health Dentistry, Sharad Pawar Dental College, DMIMS, Sawangi (Meghe), Wardha, Maharashtra, India. ${ }^{6}$ Department of Public Health Dentistry, Sharad Pawar Dental College, DMIMS, Sawangi (Meghe), Wardha, Maharashtra, India.
\end{abstract}

\section{ABSTRACT}

\section{BACKGROUND}

Oral health is the most important but often neglected entity of life. Studies have revealed that literacy skills and knowledge are strong predictors of individual's health status than age, income, employment status, education level, racial group or ethnic group. The objective of this study was to investigate how oral health literacy relates to oral health knowledge, attitude and practices among the street hawkers and fruit vendors.

\section{METHODS}

A cross-sectional study was conducted using a Marathi pretested, close ended, structured and validated questionnaire to assess oral health knowledge, attitude, practices and literacy among the street hawkers and fruit vendors. The data was collected, entered and analysed using SPSS Version 21.

\section{RESULTS}

The study shows that only $24.4 \%$ of the participants knew that teeth were important for chewing, talking and appearance, $86.7 \%$ of the participants knew that consumption of sweets causes tooth decay, 80.4\% knew that brushing teeth prevents dental caries and $91.6 \%$ knew that visiting a dentist prevents dental problems. Regarding oral hygiene practices, $16.4 \%$ used tooth paste with toothbrush, $44.4 \%$ brushed twice daily, $47.6 \%$ used tobacco more than once daily and $34.7 \%$ visited dentist when they experienced tooth ache. In case of oral health literacy, $35.6 \%$ answered correctly that bleeding gum is an inflamed gum, $32 \%$ knew that plaque is soft debris on teeth, $21.3 \%$ participants knew that fluoride strengthens the teeth and $95.1 \%$ were aware that eating/smoking tobacco causes oral cancer.

\section{CONCLUSIONS}

Our study shows that oral health literacy was limited. The awareness on oral health knowledge was good with positive attitude but practices were fair among the street hawkers and fruit vendors. Therefore, measures should be taken to improve OHL level and develop skills of self-management about oral hygiene behaviour which will promote the oral health practices.

\section{KEY WORDS}

Oral Health, Knowledge, Attitude, Practice, Street Hawkers, Fruit Vendors
Corresponding Author:

Dr. Gargi Nimbulkar,

Department of Public Health Dentistry,

Sharad Pawar Dental College, DMIMS,

Sawangi (Meghe), Wardha,

Maharashtra, India.

E-mail: garginimbulkar@gmail.com

DOI: $10.14260 /$ jemds/2020/156

Financial or Other Competing Interests: None.

How to Cite This Article:

Nimbulkar GC, Chandarana A, Sangi L, et al. Conceptual measures of oral health literacy and oral health behavior among street hawkers and fruit vendors in Wardha, Maharashtra. J. Evolution Med. Dent. Sci. 2020;9(10):716-720, DOI: 10.14260/jemds/2020/156

Submission 14-11-2019,

Peer Review 07-02-2020,

Acceptance 14-02-2020,

Published 09-03-2020.

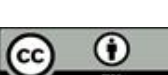




\section{BACKGROUND}

Oral health is defined by World Health Organization as "a state of being free from chronic mouth and facial pain, oral and throat cancer, oral infection and sores, periodontal (gum) disease, tooth decay, tooth loss and other disease disorders that limit an individual capacity in biting, chewing, smiling, speaking and psycho-social well-being". ${ }^{1}$ Oral health is a condition in which people can speak, eat or socialize without active (oral) disease, discomfort or embarrassment. ${ }^{2}$

Commonly found oral diseases such as caries, periodontal or gum disease, oral cancers, cleft lip and palate can be prevented or treated at an early stage. ${ }^{3}$ The demographic factors that affect its prevalence are age, sex, race, geographical location, food habits and oral hygiene practices. ${ }^{4}$ Oral health and oral diseases are common in urban areas due to improper awareness about oral health and poor socioeconomic status. ${ }^{5}$ Poor socioeconomic status and unawareness about oral health is the road block which leads the individuals to visit dental hospital and maintain good oral hygiene. Oral health concerns have continued to be substantially preventable, health issue across the life span of an individual. ${ }^{6}$

Oral health literacy (OHL) is defined as "The degree to which an individual have the capacity to obtain, process and understand basic health information and services needed to make appropriate oral health decisions". ${ }^{7}$ OHL level can be improved by helping or communicating with individuals to act on oral health information. Poor oral health can hinder one's ability to obtain, process and understand the necessary information regarding oral health that can be used to make necessary health care decisions. ${ }^{8}$ Participants with limited OHL prove to be a barrier in oral health care systems and their use of dental services. ${ }^{9}$ The availability and utilization of dental services are an important reason as well.10 The pandemic of dental diseases is a constant reminder of the pressing need for effective dental healthcare. ${ }^{11}$ Oral health plays a pivotal role in one's life. ${ }^{12}$

As there was no data regarding the oral health literacy and oral health behaviour among street hawkers and fruit vendors, this study was conducted to evaluate the oral health knowledge, attitude and practice and literacy level among them in Wardha, Maharashtra.

\section{METHODS}

This cross-sectional questionnaire-based study was conducted among the street hawkers and fruit vendors after obtaining approval from the "Institutional Ethical Committee". A pretested, close ended, structured and validated questionnaire in Marathi was designed with the help of experts.

The study was conducted among 225 street hawkers and fruit vendors aged 18 years and above. The objectives of the study were explained to them followed by the distribution of the questionnaire. They were given 30-35 minutes to answer the questions and any queries arising during filling of the questions were explained by the investigator. The first section recorded the demographic details of the participants. This was followed by the second part consisting of 25 questions that recorded knowledge (5 questions), attitude (5 questions), practices (8 questions) and oral health literacy (7 questions).

The data was collected, coded and entered in MS Excel (MS Office version 2010 developed by Microsoft). Correct answers were coded as 1 while incorrect as 0 . The data was analysed using SPSS version 21. Descriptive analysis was done.

\section{RESULTS}

\begin{tabular}{|c|c|c|}
\hline Demographic Characteristics & Categories & Frequency (\%) \\
\hline \multirow{2}{*}{ Sex } & Male & $170(75.6 \%)$ \\
\cline { 2 - 3 } & Female & $55(24.4 \%)$ \\
\hline \multirow{4}{*}{ Age } & $18-30$ years & $103(45.9 \%)$ \\
\cline { 2 - 3 } & $31-40$ years & $47(18.2 \%)$ \\
\cline { 2 - 3 } & $41-50$ years & $46(20.5 \%)$ \\
\cline { 2 - 3 } & $51-60$ years & $9(4 \%)$ \\
\cline { 2 - 3 } & 61 and above & $18(8 \%)$ \\
\hline \multirow{4}{*}{ Education } & Primary & $19(8.4 \%)$ \\
\cline { 2 - 3 } & Secondary & $27(12.0 \%)$ \\
\cline { 2 - 3 } & Higher secondary & $126(56.0 \%)$ \\
\cline { 2 - 2 } & Above higher secondary & $53(23.6 \%)$ \\
\hline \multirow{2}{*}{ Table 1. Demographic Characteristics } \\
\hline
\end{tabular}

Table 1 presents demographic characteristics of participants. Among 225 participants, there were 170 (75.6\%) males and 55 (24.4\%) females. The age were categorized into different age groups out of which 103 (45.9\%) participants were of 18 to 30 years, 47 (18.2\%) participants were of 31 to 40 years, 46 (20.5\%) participants were of 41 to 50 years, 9 (4\%) participants were of 51 to 60 years and $18(8 \%)$ participants were 61 years and above. According to the level of education, 19 (8.4\%) participants had primary education, 27 (12\%) participants had secondary education, $126(56 \%)$ participants had higher secondary and $53(23.6 \%)$ participants had above higher secondary education.

\begin{tabular}{|c|c|c|}
\hline Question & Options & Frequency (\%) \\
\hline \multirow{4}{*}{ Importance of teeth } & Chewing & $134(59.6 \%)$ \\
\hline & Talking & $12(5.3 \%)$ \\
\hline & Appearance & $24(10.7 \%)$ \\
\hline & All of the above & $55(24.4 \%)$ \\
\hline \multirow{3}{*}{$\begin{array}{c}\text { Carious/decayed tooth affects } \\
\text { the teeth appearance }\end{array}$} & Yes & $182(80.9 \%)$ \\
\hline & No & $23(10.2 \%)$ \\
\hline & Don't know & $20(8.9 \%)$ \\
\hline \multirow{3}{*}{$\begin{array}{l}\text { Consumption of sweets } \\
\text { causes tooth decay }\end{array}$} & Yes & $195(86.7 \%)$ \\
\hline & No & $14(6.2 \%)$ \\
\hline & Don't know & $16(7.1 \%)$ \\
\hline \multirow{3}{*}{$\begin{array}{l}\text { Brushing teeth prevents } \\
\text { dental caries }\end{array}$} & Yes & $181(80.4 \%)$ \\
\hline & No & $28(12.4 \%)$ \\
\hline & Don't know & $16(7.1 \%)$ \\
\hline \multirow{3}{*}{$\begin{array}{l}\text { Visits to dentist prevents } \\
\text { Dental problems }\end{array}$} & Yes & $106(91.6 \%)$ \\
\hline & No & $19(8.4 \%)$ \\
\hline & Don't know & $0(0 \%)$ \\
\hline \multicolumn{3}{|c|}{$\begin{array}{l}\text { Table 2. Distribution of Knowledge about } \\
\text { Oral Health among the Participants }\end{array}$} \\
\hline
\end{tabular}

Table 2 shows distribution of knowledge among the participants. When asked about the importance of teeth 134 (59.6\%) participants answered chewing, 12 (5.3\%) answered talking, $24(10.7 \%)$ answered appearance, while 55 (24.4\%) correctly answered all of the above. Approximately 182 $(80.9 \%)$ answered rightly that carious or decayed tooth can affect teeth appearance while 23 (10.2\%) participants wrongly answered no and $20(8.9 \%)$ participants said that they were unaware about it. There were 195 (86.7\%) participants who answered correctly that consumption of 
sweet causes tooth decay while 14 (6.2\%) participants answered incorrectly as no and 16 (7.1\%) answered that they didn't know the correct answer. Brushing teeth prevents dental caries was known correctly to 181 (80.4\%) participants, while $28(12.4 \%)$ answered incorrectly as no and $16(7.4 \%)$ of the participants answered that they were unknown about it. Approximately 206 (91.6\%) participants answered rightly that regular visit to the dentist prevents dental problems while 19 (8.4\%) answered wrongly as no.

\begin{tabular}{|c|c|c|}
\hline Question & Options & Frequency (\%) \\
\hline \multirow{3}{*}{$\begin{array}{c}\text { How often do you visit a } \\
\text { dentist }\end{array}$} & During tooth ache & $149(66.2 \%)$ \\
\hline & Often & $27(12 \%)$ \\
\hline & Never visited & $49(21.8 \%)$ \\
\hline \multirow{2}{*}{$\begin{array}{l}\text { Is teeth important as any } \\
\text { part of the body }\end{array}$} & Yes & $211(93.8 \%)$ \\
\hline & No & $14(6.2 \%)$ \\
\hline \multirow{2}{*}{$\begin{array}{l}\text { Regular visit to the dentist } \\
\text { is necessary }\end{array}$} & Yes & $194(86.2 \%)$ \\
\hline & No & $31(13.8 \%)$ \\
\hline \multirow{4}{*}{$\begin{array}{l}\text { Feelings at first visit } \\
\text { to the dentist }\end{array}$} & Scared and reluctant & $45(20.0 \%)$ \\
\hline & Slightly afraid & $62(27.6 \%)$ \\
\hline & Very slightly afraid & $27(12.0 \%)$ \\
\hline & Never afraid & $45(20 \%)$ \\
\hline \multirow{5}{*}{$\begin{array}{l}\text { Pain felt at the time of first } \\
\text { visit to the dentist }\end{array}$} & No dental pain & $58(25.8 \%)$ \\
\hline & Severe dental pain & $54(24.4 \%)$ \\
\hline & Moderate dental pain & $31(13.8 \%)$ \\
\hline & Uncomfortable & $22(9.8 \%)$ \\
\hline & Felt nothing & $13(5.8 \%)$ \\
\hline \multicolumn{3}{|c|}{ Table 3. Attitude of Participants towards Oral Health } \\
\hline
\end{tabular}

\begin{tabular}{|c|c|c|}
\hline Question & Options & Frequency (\%) \\
\hline \multirow{6}{*}{ Aids used to clean teeth } & Tooth paste with toothbrush & $37(16.4 \%)$ \\
\hline & Tooth paste with finger & $79(35.1 \%)$ \\
\hline & Tooth powder with toothbrush & $43(19.1 \%)$ \\
\hline & Tooth powder with finger & $57(25.3 \%)$ \\
\hline & Neem stick & $9(4.0 \%)$ \\
\hline & Nus/mishri & 0 \\
\hline \multirow{4}{*}{ Type of toothbrush used } & Big head, hard bristles & $80(35.6 \%)$ \\
\hline & Big head, soft bristles & $40(17.8 \%)$ \\
\hline & Small head, soft bristles & $68(30.2 \%)$ \\
\hline & Small head, hard bristles & $37(16.4 \%)$ \\
\hline \multirow{4}{*}{$\begin{array}{l}\text { Frequency of changing } \\
\text { toothbrush }\end{array}$} & $1-3$ months & $53(23.6 \%)$ \\
\hline & $4-6$ months & $130(57.8 \%)$ \\
\hline & $7-12$ months & $27(12 \%)$ \\
\hline & More than 1 year & $15(6.7 \%)$ \\
\hline \multirow{4}{*}{ Time of brushing teeth } & In the morning & $94(41.8 \%)$ \\
\hline & In the evening & $49(21.8 \%)$ \\
\hline & After meals & $72(32.0 \%)$ \\
\hline & After deserts/sweets & $10(4.4 \%)$ \\
\hline \multirow{3}{*}{ Frequency of brushing } & Brushing once a day & $107(47.6 \%)$ \\
\hline & Brushing twice a day & $100(44.4 \%)$ \\
\hline & More than twice a day & $18(8.0 \%)$ \\
\hline \multirow{2}{*}{ Duration of cleaning teeth } & Less than 3 minutes & $95(42.2 \%)$ \\
\hline & 3 minutes or more & $130(57.8 \%)$ \\
\hline \multirow{4}{*}{ Method of cleaning teeth } & Horizontal & $70(31.1 \%)$ \\
\hline & Circular & $30(13.3 \%)$ \\
\hline & Vertical & $86(38.2 \%)$ \\
\hline & No systemic method & $39(17.3 \%)$ \\
\hline \multirow{2}{*}{$\begin{array}{c}\text { Rinsing mouth after } \\
\text { eating }\end{array}$} & Yes & $130(57.8 \%)$ \\
\hline & No & $95(42.2 \%)$ \\
\hline \multirow{5}{*}{$\begin{array}{l}\text { Use of tobacco } \\
\text { containing products }\end{array}$} & Beedi & $26(11.6 \%)$ \\
\hline & Guthka & $36(16.0 \%)$ \\
\hline & Cigarette & $17(7.6 \%)$ \\
\hline & Tobacco containing betel leaf & $45(20.0 \%)$ \\
\hline & Kharra & $101(44.9 \%)$ \\
\hline \multirow{4}{*}{$\begin{array}{c}\text { Frequency of using } \\
\text { tobacco products }\end{array}$} & Once in a month & $32(14.2 \%)$ \\
\hline & Once in a week & $40(17.8 \%)$ \\
\hline & Often & $44(19.6 \%)$ \\
\hline & More than once in a day & $107(47.6 \%)$ \\
\hline \multirow{2}{*}{ Ever visited a dentist } & Yes & $174(77.3 \%)$ \\
\hline & No & $51(22.7 \%)$ \\
\hline \multirow{3}{*}{$\begin{array}{l}\text { If yes, when was the } \\
\text { last visit }\end{array}$} & Less than 1 year & $71(31.6 \%)$ \\
\hline & $1-2$ years & $75(33.3 \%)$ \\
\hline & 3 years or more & $30(13.3 \%)$ \\
\hline \multirow{5}{*}{$\begin{array}{c}\text { Reason for visiting } \\
\text { dentist }\end{array}$} & Regular check up & $55(24.4 \%)$ \\
\hline & Tooth ache & $78(34.7 \%)$ \\
\hline & Filling/restoration & $20(8.9 \%)$ \\
\hline & Extraction & $15(6.6 \%)$ \\
\hline & Gum bleeding & $8(3.6 \%)$ \\
\hline
\end{tabular}

Table 3 presents attitudes of the participants towards oral health. Of all the participants, 149 (66.2\%) visited a dentist when they experienced tooth ache, 27 (12\%) often visited a dentist and 49 (21.8\%) never visited a dentist. Approximately 211 (93.8\%) answered correctly that teeth is as important as any other part of the body while $14(6.2 \%)$ answered incorrectly as no. About 194 (86.2\%) answered rightly that regular visit to the dentist is necessary while 31 $(13.8 \%)$ wrongly answered that it was not necessary. Around $45(20 \%)$ participants expressed that they were scared and reluctant when they first visited the dentist, 62 (27.6\%) were slightly afraid, $27(12 \%)$ were very slightly afraid whereas 45 $(20 \%)$ were not afraid at all. When asked about the emotional status at the time of first visit to the dentist, 58 (25.8\%) had no dental pain, $54(24.4 \%)$ had severe dental pain, 31 (13.8\%) had moderate dental pain, 22 (9.8\%) were uncomfortable and $13(5.8 \%)$ felt nothing during the treatment.

Table 4 shows practices pertaining to maintenance of oral hygiene among the participants. For cleaning the teeth, 37 (16.4\%) used tooth paste with tooth brush, 79 (35.1\%) used tooth paste with finger, $43(19.1 \%)$ used tooth powder with tooth brush, 57 (25.3\%) used tooth powder with finger and 9 (4\%) used neem stick to clean the teeth. Big head and hard bristles type of toothbrush was used by 80 (35.6\%), 40 (17.8\%) used big head and soft bristles toothbrush, 68 (30.2\%) used small head and soft bristles toothbrush and 37 (16.4\%) used small head and hard bristles toothbrush. After every 1 to 3 months 53 (23.6\%) changed their toothbrush, $130(57.8 \%)$ changed after 4 to 6 months, 27 (12\%) changed their toothbrush after 7 to 12 months and 15 (6.7\%) changed their toothbrush after more than 1 year. Out of all the participants, $94(41.8 \%)$ brushed their teeth in the morning, $49(21.8 \%)$ brushed their teeth in the evening, 72 (32\%) brushed their teeth after meals and $10(4.4 \%)$ brushed their teeth after consumption of sweets/desserts. Around 107 (47.6\%) brushed their teeth once a day, 100 (44.4\%) brushed their teeth twice a day and $18(8 \%)$ brushed their teeth more than twice a day. Approximately 95 (42.2\%) cleaned their teeth for less than 3 minutes while 130 (57.8\%) cleaned their teeth for 3 minutes or more than that. Horizontal type of cleaning was practiced by 70 (31.1\%) participants, 30 (13.3\%) used circular method, 86 (38.2\%) used vertical method and $39(17.3 \%)$ of the participants had no specific method of cleaning.

Approximately 130 (57.8\%) rinsed their mouth after eating while $95(42.2 \%)$ did not. Out of the participants 26 (11.6\%) had habit of using beedi, 36 (16\%) used guthka, 17 (7.6\%) used cigarette, 45 (20\%) used tobacco containing beetle leaf and 101 (44.9\%) used kharra. Tobacco product was used by $32(14.2 \%)$ participants once in a month, 40 (17.8\%) participants used once in a week, 44 (19.6\%) participants used very often, 107 (47.6\%) participants used more than once in a day. Of all the participants 174 (77.3\%) already visited a dentist while $51(22.7 \%)$ never visited a dentist. Approximately 71 (31.6\%) visited a dentist less than 1 year ago, 75 (33.3\%) visited 1-2 years ago and 30 (13.3\%) participants visited dentist more than 3 years ago. Among the participants $55(24.4 \%)$ visited a dentist for dental check-up, $78(34.7 \%)$ visited due to tooth ache, 20 (8.9\%) visited for filling/restoration, $15(6.6 \%)$ visited for extraction of tooth and $8(3.6 \%)$ visited due to gum bleeding.

Table 5 shows oral health literacy among the participants. Out of all the participants, 80 (35.6\%) answered correctly 
that bleeding gum is an inflamed gum while 78 (34.7\%) incorrectly answered that bleeding gum is a healthy gum, 32 $(14.2 \%)$ as gingival recession and $35(15.6 \%)$ answered that they didn't know. Around 72 (32.0\%) gave right answer that plaque is soft debris on the teeth while $26(11.6 \%)$ wrongly answered that plaque is hard debris on the teeth, $23(10.2 \%)$ as stains and $104(46.2 \%)$ answered that they didn't know. Around $37(16.4 \%)$ knew the correct number of deciduous teeth while 188 (83.6\%) answered incorrectly. Among the participants $103(45.8 \%)$ rightly answered the number of permanent teeth whereas 122 (54.2\%) participants didn't know the correct answer.

\begin{tabular}{|c|c|c|}
\hline Question & Options & Frequency (\%) \\
\hline \multirow[t]{4}{*}{ What is gum bleeding } & Healthy gums & $78(34.7 \%)$ \\
\hline & Inflamed gums & $80(35.6 \%)$ \\
\hline & Gingival recession & $32(14.2 \%)$ \\
\hline & Don't know & $35(15.6 \%)$ \\
\hline \multirow[t]{4}{*}{ What does plaque mean } & Soft debris on the teeth & $72(32.0 \%)$ \\
\hline & Hard debris on the teeth & $26(11.6 \%)$ \\
\hline & Stains on the teeth & $23(10.2 \%)$ \\
\hline & Don't know & $104(46.2 \%)$ \\
\hline \multirow[t]{2}{*}{ Number of deciduous teeth } & Correct & $37(16.4 \%)$ \\
\hline & Incorrect & $188(83.6 \%)$ \\
\hline \multirow[t]{2}{*}{ Number of permanent teeth } & Correct & $103(45.8 \%)$ \\
\hline & Incorrect & $122(54.2 \%)$ \\
\hline \multirow[t]{2}{*}{ Sweets affect the teeth adversely } & Correct & $194(86.2 \%)$ \\
\hline & Incorrect & $31(13.8 \%)$ \\
\hline \multirow[t]{2}{*}{ Fluoride strengthens the teeth } & Correct & $48(21.3 \%)$ \\
\hline & Incorrect & $177(78.7 \%)$ \\
\hline \multirow{2}{*}{$\begin{array}{c}\text { Smoking/eating tobacco causes } \\
\text { oral cancer }\end{array}$} & Correct & $214(95.1 \%)$ \\
\hline & Incorrect & $11(4.9 \%)$ \\
\hline \multicolumn{3}{|c|}{ Table 5. Oral Health Literacy among the Participants } \\
\hline
\end{tabular}

Approximately $194 \quad(86.2 \%)$ were aware that consumption of sweets affects the teeth adversely while 31 (13.8\%) were unaware of it. Around 48 (21.3\%) participants knew that fluoride strengthens the teeth while 177 (78.7\%) didn't know about it. Approximately 214 (95.1\%) were aware that eating/smoking tobacco causes oral cancer while 11 (4.9\%) participants answered incorrectly as no.

\section{DISCUSSION}

The current study was conducted to assess the oral health knowledge, attitude, and practice and literacy level among street hawkers and fruit vendors in Wardha, Maharashtra. In our study approximately one third knew that teeth were important for chewing, talking and appearance that showed awareness among the participants was very low. Out of all the participants' majority were aware that caries affected the teeth appearance. The study conducted by Mahmod K. AlOmiri et al showed similar results. ${ }^{5}$ Our study showed that majority of the participants knew consumption of sweets causes tooth decay which was similar with the study conducted by Mahmod K. Al-Omiri et al among school children. ${ }^{5}$ Results were in contrast with study conducted by Mathur A et al among school children where approximately half of the school children knew that consumption of sweets causes tooth decay. ${ }^{13}$ This may be because of the difference in age. Majority of the participants knew that brushing teeth and visiting the dentist prevents dental caries this could be because of knowledge gained with age.

In our study majority of the participants knew that the teeth were an important part of the body. Approximately another two third of the participants visited a dentist only when they experienced tooth ache. Results were in contrast with study conducted by Mathur A. et al and Mahmod K. AlOmiri et al among school children wherein approximately one third visited a dentist when they experienced tooth ache.5,13 This showed that the dental visiting behaviour of street hawkers and vendors was symptomatic rather than preventive orientation. Additionally, it could be due to their poor financial status and negligence. Our study showed that majority of the participants knew that the regular visit to the dentist is recommended. The results of the study conducted by Mahmod K. Al-Omiri et al and Blaggana A et al were similar.5,14 Results were not in consensus with study conducted by Mathur A. et al where approximately half of the participants were aware that regular visit to the dentist was necessary which could be due to differences in the age group and oral health awareness. ${ }^{13}$ In our study majority of participants experienced varying degrees of pain during their first dental visit which could be mainly attributed to the symptomatic orientation. About less than one fourth of participants were not afraid for their first visit to dentist which is similar to the results reported by Blaggana A. et al. ${ }^{14}$ This shows that fear of dentists and the inadvertent attitude could be one of the major barriers in utilization of dental services.

Although Majority of the population visited a dentist a very few were found to visit within the last one year out of which a majority of them were for tooth ache rather than regular dental check-up. In the study majority of the participants brushed once daily in the morning for about 3 minutes or more using the vertical method of cleaning which was in contrast to Blaggana A. et al study where vertical method was the least which could be attributed to lack of knowledge on brushing techniques. ${ }^{14}$ It was found that approximately one third brushed their teeth twice a day which is almost similar with the study conducted by Blaggana A. et al but in contrast with the study conducted by Mathur A. et al wherein less than one third brushed their teeth twice a day which could be due to the lack of awareness about oral hygiene practices. ${ }^{13,15}$ Although it was recommended to use toothpaste and brush, less than a one fourth used it and changed their brushes in 3 months. It was seen that more than one third of the population used a tooth paste with the finger which could be attributed to cultural preferences and lack of knowledge. In Our study it was found that all the participants had a habit of using tobacco products and more than one third used it daily. It was also found that the majority of the participants knew that smoking or eating tobacco causes oral cancer. It also reflects their injudicious attitude towards their own wellbeing in spite of knowing the hazards of tobacco consumption.

In our study it was seen that less than one third of the participants knew the correct number of deciduous teeth and permanent teeth. It also showed that majority of the participants knew that consumption of sweets caused tooth decay which was similar to the study conducted by Mahmod $\mathrm{K}$. Al-Omiri et al among school children. ${ }^{5}$ Results were in contrast with study conducted by Mathur A et al among school children where approximately half of the school children knew that consumption of sweets caused tooth decay. ${ }^{13}$ This might be due to the difference in age and oral health literacy. In the study less than a one third defined plaque as soft debris on teeth; these results were quite 
similar to Mathur A. et al study. ${ }^{13}$ However in Mahmod K. AlOmiri et al study less than a one fourth knew the correct answer. ${ }^{13}$ This could be connected to the dissimilarity in literacy level and geographical location. It was also found that less than a one third defined gum bleeding as an inflamed gum which was similar to Mathur A. et al study. ${ }^{13}$ But these results were in contrast to the study conducted by Mahmod $\mathrm{K}$. Al-Omiri et al wherein more than a half of the participants knew that gum bleedings were inflamed gums. ${ }^{5}$

The study was based on self-reported system where social desirability bias could occur which could get involved in the individual interpretations from the responses they gave, it may lead to overestimation of correct answers. In our study convenience sample of adults took part in filling the data or questionnaire to examine the oral health literacy level among them. Therefore, one should be careful when explaining the results relating to self-assessment behaviour.

\section{CONCLUSIONS}

Oral health literacy level was limited and the awareness about oral health knowledge, attitude and practices was poor among the street hawkers and fruit vendors. Increase in oral health literacy level can prevent the diseases that can progress, and can improve the literacy level among them. Therefore, awareness should be increased in order to improve OHL level and help to improve self-management skills which will in turn promote the oral health behaviours and practices. The current study will be helpful in planning oral health awareness programs.

\section{REFERENCES}

[1] Kaur S, Kaur B, Ahluwalia SS. Oral health knowledge, attitude and practices amongst health professionals in Ludhiana, India. Dentistry 2015;5 (7):315-20.

[2] Karnam RR, Kumar NS, Eshwar S, et al. Cognitive ability as a determinant of socioeconomic and oral health status among Adolescent College Students of Bengaluru, India. J Clin Diagn Res 2016;10 (12):ZC62-6.

[3] Zhu L, Petersen PE, Wang HY, et al. Oral health knowledge, attitudes and behavior of adults in China. Int Dent J 2005;55 (4):231-41.
[4] Patil S, Ranka R, Chaudhary M, et al. Prevalence of dental caries and gingivitis among pregnant and non-pregnant women. J Datta Meghe Inst Med Sci Univ 2018;13 (1):447.

[5] Al-Omiri M, Al-Wahadni A, Saeed K. Oral health attitudes, knowledge and behavior among school children in North Jordan. Journal of Dental Education 2006;70 (2):179-87.

[6] Baliga SM. Child oral health-care literacy in India: Can access to services be improved? J Indian Soc Pedod Dent 2019;37 (1):1-2.

[7] Gomez MS, Sujatha BK. Assessment of oral health literacy among patients attending Malabar dental college and research centre in Kerala. A cross sectional survey. J Indian Assoc Public Health Dent 2015;13 (3):328-30.

[8] Sen S, Deolia S, Chechediya N, et al. Relationship between oral health literacy and oral health status among class four workers of Wardha, Maharashtra, India. University Journal of Dental Sciences 2017;2 (3):25-40.

[9] Sistani MMN, Virtanen JI, Yazdani R, et al. Association of oral health behaviour and the use of dental services with oral health behavior and the use of dental services with oral heath literacy among adults in Tehran, Iran. Eur J Dent 2017;11 (2):162-7.

[10] Sen S, Balwani T, Sahu A, et al. Tooth loss and associated risk factors among rural population of Wardha District: a cross-sectional study. J Indian Assoc Public Health Dent 2018;16 (1):11-7.

[11] Khemka S, Baliga S, Thosar N. Approaches to improve access to dental care services. Int Dent Med J Adv Res 2015;1 (1):1-4.

[12] Kriplani R, Bahadure R, Thosar N. Full mouth rehabilitation of early childhood caries: a case report. Journal of Datta Meghe Institute of Medical Sciences University 2012;7 (1):51-3.

[13] Al-Darwish MS. Oral health knowledge, behaviour and practices among school children in Qatar. Dent Res J (Isfahan) 2016;13 (4):342-53.

[14] Blaggana A, Grover V, Anjali, et al. Oral health knowledge, attitudes and practice behavior among secondary school children in Chandigarh. J Clin Diagn Res 2016;10 (10):ZC01-ZC6.

[15] Rai S, Shodan M, Sheety PJ. Conceptual measure of oral h0ealth literacy level among patients visiting a private dental institution in Dharwad: a cross-sectional questionnaire study. J Indian Assoc Public Health Dent $2015 ; 13$

(4):492-6 